\title{
Educação em saúde no contexto da Saúde da Família na perspectiva do usuário *
}

\author{
Maria Fernanda Santos Figueiredo ${ }^{1}$ \\ João Felício Rodrigues Neto ${ }^{2}$ \\ Maisa Tavares de Souza Leite ${ }^{3}$
}

FIGUEIREDO, M.F.S.; RODRIGUES NETO, J.F.; LEITE, M.T.S. Health education in the context of family health from the user's perspective. Interface - Comunic., Saude, Educ., v.16, n.41, p.315-29, abr./jun. 2012.

This study aimed to understand users' perspectives regarding health education and its significance in everyday life, through qualitative, descriptive and exploratory research. The participants were eleven users registered with a family health team in Montes Claros, MG, Brazil, whose frequency of attendance of educational activities carried out in 2007, in health education groups, was not less than five times. Data were gathered through unstructured interviews and were analyzed by means of discourse analysis. The results revealed three empirical categories: "Health education practice in the family health team", "Health education provides meaningful learning" and "Health education favors changes in users' health". The health education groups, in which the sessions used pedagogical approaches of conditioning, transmission and/or problem-solving, favored meaningful learning among users. This enabling changes regarding living habits, use of autonomy and taking responsibility for health.

Keywords: Health Education. Learning. Primary Health Care. Family Health. Qualitative research.
Objetivou-se compreender a perspectiva de usuários sobre Educação em Saúde e seu significado no cotidiano, mediante pesquisa qualitativa, descritiva e exploratória. Os participantes foram 11 usuários cadastrados em uma Equipe de Saúde da Família em Montes Claros, MG, Brasil, com frequência igual ou superior a cinco atividades em grupos educativos desenvolvidos na unidade de saúde em 2007. Os dados, coletados em entrevistas não estruturadas, foram analisados pela análise do discurso. Resultados revelaram três categorias empíricas: "A prática de Educação em Saúde na Equipe de Saúde da Família"; "A Educação em Saúde propicia uma aprendizagem significativa"; "A Educação em Saúde favorece mudanças na saúde do usuário". Os grupos educativos, em cujas sessões utilizaram-se pedagogias de condicionamento, transmissão e/ou problematização, favoreceram aprendizagem significativa do usuário, propiciando mudanças nos hábitos de vida, no exercício da autonomia e na responsabilização pela saúde.

Palavras-chave: Educação em Saúde. Aprendizagem. Atenção Primária à Saúde. Saúde da Família. Pesquisa qualitativa.

\footnotetext{
Elaborado com base em Figueiredo (2010): pesquisa aprovada pelo Comitê de Ética em Pesquisa da Universidade Estadual de Montes Claros. 1,3 Departamento de Enfermagem, Centro de Ciências Biológicas e da Saúde, Universidade Estadual de Montes Claros.

2 Departamento de Clínica Médica, Centro de Ciências Biológicas e da Saúde, Universidade Estadual de Montes

Claros. Rua Professor Dr. Rui Braga, s/n, Campus Universitário, Bairro Vila Mauricéia. Montes Claros, MG, Brasil. 39.401-089.
}

joao.felicio@unimontes.br 


\section{Introdução}

A educação em saúde surgiu em 1909, nos Estados Unidos da América, como estratégia de prevenção de doenças (Alves, Aerts, 2011). Trata-se de um campo multifacetado, que abarca diversas concepções, tanto das áreas da educação quanto da saúde (Schall, Struchiner, 1999). O seu conceito e propósito foram marcados e influenciados pelas mudanças de paradigmas e transformações ocorridas no setor da saúde e da educação ao longo da história (Rocha, Schall, Lemos, 2010; Alves, 2005; Schall, Struchiner, 1999).

A atividade educativa realizada no campo da saúde, por várias décadas, se configurou como uma prática normalizadora, com um discurso higienista e com a finalidade de controlar e prevenir doenças, responsabilizando individualmente o sujeito pela sua condição de saúde (Rocha, Schall, Lemos, 2010; Alves, 2005). Esse contexto foi influenciado por uma concepção de educação baseada na transmissão e na reprodução de conhecimentos, sem uma reflexão crítica, e na condição de passividade do educando, cujo pensamento e ação são controlados pelo educador (Bordenave, Pereira, 2007; Freire, 2007, 2005; Gadotti, 2004). O entendimento sobre a saúde estava reduzido ao controle de agentes biológicos causadores ou transmissores de doenças (Rocha, Schall, Lemos, 2010).

Com o decorrer dos anos, percebeu-se que tal forma de educar em saúde tem se tornado insuficiente, já que não contempla as discussões de um conceito ampliado de saúde, considerando as suas múltiplas dimensões (biopsicossociais) e a necessidade de se promover a saúde, presentes, inicialmente, no Relatório de Lalonde (Lalonde, 1974), na Conferência Internacional sobre Cuidados Primários em Saúde (OMS, 1978), e na Primeira Conferência Internacional sobre Promoção da Saúde (OMS, 1986). No Brasil, as mudanças estruturais ocorridas, após o período de ditadura, no serviço de saúde, com a criação do Sistema Único de Saúde, demandaram também uma nova forma de educar em saúde (Freitas, 2010).

Para tanto, a educação em saúde deve estar ancorada na concepção da educação como potencial para contribuir para o desenvolvimento do indivíduo, de modo a estimulá-lo a refletir, desenvolver a consciência crítica, exercer a sua autonomia e cidadania, e criar, possibilitando-Ihe transformar a realidade e escrever a sua própria história (Bordenave, Pereira, 2007; Freire, 2007; Perrenoud, 2005; Morin, 2002).

Nesse sentido, as atividades educativas em saúde devem orientar a construção de conhecimentos e o desenvolvimento de práticas relativas à saúde, com vistas à prevenção de doenças e à promoção de saúde (Rocha, Schall, Lemos, 2010), de forma a abranger a participação de toda a população no contexto de sua vida cotidiana, e não apenas as pessoas sob risco de adoecer (Schall, Struchiner, 1999). Têm a finalidade de potencializar o empoderamento dos indivíduos e estimular o desenvolvimento da responsabilidade e da autonomia por sua saúde, tornando-os capazes de tomarem suas próprias decisões, de modo a favorecerem mudanças nas suas condições de saúde (Silva et al., 2009; Trezza, Santos, Santos, 2007; Alves, 2005).

A Saúde da Família, estratégia utilizada pelo Ministério da Saúde para reorganização da Atenção Primária à Saúde no Brasil, constitui um espaço privilegiado para desenvolvimento de práticas educativas em saúde, e está em expansão em todo o território nacional (Alves, 2005). Uma de suas atribuições é a prática de Educação em Saúde, que deve ser desenvolvida pelos membros da equipe (Brasil, 1997).

Considerando-se que a visão da educação como potencial de transformar o cotidiano das pessoas e da população, buscando a promoção da saúde, ainda é recente na prática, sobretudo quando se aprecia a percepção dos usuários - pois são estes que devem apresentar as mudanças de hábitos e atitudes - e somando-se à necessidade de se avançar com ações que favoreçam a utilização da educação em saúde, é que se propõe a realização deste trabalho com o objetivo de se compreender a perspectiva dos usuários cadastrados em uma Equipe de Saúde da Família (ESF), na cidade de Montes Claros, norte de Minas Gerais, sobre a educação em saúde e o seu significado no cotidiano. 


\section{Metodologia}

Trata-se de uma pesquisa qualitativa, de caráter descritivo e exploratório, realizada na cidade de Montes Claros - Minas Gerais, em uma ESF, com território de abrangência correspondente a seis microáreas, com um total de, aproximadamente, setecentos e vinte famílias. A equipe é composta por: um médico, um enfermeiro, um cirurgião-dentista, um técnico de enfermagem e seis agentes comunitários de saúde (ACS).

A escolha do referencial teórico e metodológico levou em consideração a abordagem dialética, analisada segundo Habermas (1989) e Freire (2005), que contribui para que se contextualizem, de forma crítica, a história e a linguagem dos problemas de saúde e das práticas sociais da área.

Os participantes dessa pesquisa foram identificados por meio da ata de registro de frequência dos usuários da ESF nos grupos de educação em saúde, ocorridos em 2007, e selecionados a partir dos seguintes critérios de inclusão: ser usuário cadastrado na ESF, com idade a partir de 18 anos e participação igual ou superior a cinco vezes em qualquer um dos grupos educativos realizados pela equipe - grupo de saúde mental, grupo de hipertensos, grupo de portadores de diabetes, grupo de obesidade, grupo de gestantes e grupo de planejamento familiar - no ano de 2007. O critério de exclusão foi a não-aceitação em participar da pesquisa.

O número de participantes foi considerado suficiente quando os dados da pesquisa refletiram a totalidade das múltiplas dimensões do objeto deste estudo e se tornaram repetitivos (Minayo, 2007).

A coleta de dados foi realizada por um dos autores, no domicílio dos usuários, após a leitura dos objetivos da pesquisa e obtenção da assinatura do Termo de Consentimento Livre e Esclarecido, através de uma entrevista não estruturada, com as seguintes questões norteadoras: "Para você, como foi participar de um grupo de educação em saúde, e como os mesmos aconteceram?"; "O que mudou após a sua participação no grupo de educação em saúde?"; "Como se sente em relação a essas atividades?".

As entrevistas foram gravadas e, em seguida, transcritas, o que possibilitou o registro fidedigno de todas as informações fornecidas pelos entrevistados. Os participantes foram identificados com legendas, mantendo-se $o$ anonimato.

Para a análise dos dados, foi utilizada a técnica de análise do discurso, seguindo a corrente de pensamento de Pêcheux (2002). Após leitura e releitura do material, emergiram as primeiras categorias que, posteriormente, com o aprofundamento da leitura e da reflexão acerca das condições de produção dos discursos analisados, foram agrupadas em categorias mais abrangentes. Verificaram-se os sentidos relacionados ao discurso e seus efeitos, indo além do texto, observando-se, em suas entrelinhas, os processos de significação, as convergências e divergências, e relacionando-se o interdiscurso e o intradiscurso.

As categorias empíricas foram confrontadas com as analíticas, buscando-se as relações entre ambas, e subdivididas em componentes menores, as subcategorias.

Submeteu-se esta pesquisa, que está em conformidade com os princípios da Declaração de Helsinque, à apreciação do Comitê de Ética em Pesquisa da Universidade Estadual de Montes Claros UNIMONTES, a qual foi aprovada.

\section{Resultados e discussão}

Foram entrevistados 11 usuários. O perfil dos participantes foi caracterizado por seis adultos - na faixa etária entre 45 e 59 anos - e cinco idosos - na faixa etária entre sessenta e 75 anos - de ambos os sexos (sete do sexo feminino e quatro do sexo masculino). Seis eram casados, três, separados, e dois, viúvos. Em relação à escolaridade, dois eram analfabetos, oito tinham de um a três anos de estudo, e um possuía mais do que oito anos. Seis participavam dos grupos educativos para portadores de diabetes e cinco dos grupos educativos para hipertensos. 
O perfil dos participantes, marcado pela baixa escolaridade e faixa etária elevada, demonstra a sua vulnerabilidade, influenciada pelo contexto da sua vida, em que apresentou pouca oportunidade de vivenciar o processo educativo, necessário para se tornar cidadão, exercer autonomia e controle sobre a sua vida (Freire, 2007; Perrenoud, 2005; Morin, 2002). Em sua trajetória de vida, vivenciou a valorização do saber do profissional de saúde, e o seu papel era de seguir fielmente as suas recomendações, o que o colocou em uma condição de passividade e, até mesmo, de alienação (Freire, 2007). É possível que os participantes estejam buscando, nos grupos educativos estruturados por doenças, o controle de sua doença, esperando uma educação prescritiva.

Os discursos analisados dos onze indivíduos entrevistados revelaram três categorias empíricas:

\section{A prática de educação em saúde na ESF}

Nesta categoria, foi considerada a forma de realização das atividades de educação em saúde no cotidiano da ESF, analisando-se o espaço físico e os recursos utilizados, as pedagogias adotadas, bem como os temas discutidos, de onde emergiram, respectivamente, as três subcategorias.

Dentre as atribuições a serem desenvolvidas pela ESF, destaca-se a realização das atividades de Educação em Saúde (Brasil, 1997). A seguir, discute-se como tais atividades, realizadas através de grupos educativos, estavam estruturadas na ESF.

\section{Espaço físico e recursos utilizados}

Os grupos educativos aconteciam na própria unidade de saúde, em uma sala de reuniões, mas, algumas vezes, quando havia um número maior de pessoas, eram realizados em outros locais, conforme os seguintes relatos:

"as pessoas iam chegando e sentavam e ficavam esperando o médico chegar, as meninas (ACS) organizavam a sala (de reuniões) [...]". (E8)

"Tinha vez que aquele salão (da igreja católica) não cabia o povo [...]". (E7)

Os profissionais de saúde responsáveis pela condução das práticas educativas eram o médico e o enfermeiro, com auxílio dos ACS, segundo depoimento:

"A enfermeira e o médico (que conduziam as atividades educativas), quando o médico não estava, a enfermeira e a outra ajudante (ACS) (que conduziam)". (E3)

De acordo com os participantes, os encontros aconteciam uma vez por mês e eram realizados em dias e horários variáveis:

\footnotetext{
"Os grupos são muito bons, eu sei que (aconteciam) uma vez por mês [...]". (E1)

"[...] dependendo da hora da reunião, muita gente não dava para ir. Talvez nesse horário (pela manhã) muita gente trabalha [...]". (E9)
}

A falta de padronização de horário, apontada como um fator dificultador para a participação do usuário nas sessões educativas, pode ser devida às atribuições dos profissionais de saúde, os quais as realizavam em horários mais apropriados para eles, sem considerar as necessidades dos usuários.

Em estudo realizado sobre a participação popular na gestão da ESF, em duas comunidades do município de Campina Grande, Paraíba, verificou-se, na percepção dos profissionais de saúde, que o horário e a periodicidade dos grupos educativos são fatores que inibem ou dificultam a participação dos usuários nas atividades educativas (Lacerda, Santiago, 2007). 
Observou-se, no presente trabalho, que os participantes aguardavam passivamente a chegada do profissional para iniciar as atividades - conduta que caracteriza, ainda, uma relação de dominação entre educando e educador (Freire, 2005), devido ao status imposto historicamente aos profissionais de saúde (Villa, Aranha, 2009), reforçado pela falta do processo de acolhimento e humanização e pela organização do serviço de saúde, a partir das necessidades dos profissionais, com usuário exercendo o papel de "paciente", como verificado neste depoimento:

"A gente chegava, sentava, esperava o horário deles (dos profissionais) [...]".

Em contraposição aos fatores dificultadores, os participantes relataram o uso de recursos, como jogos e brincadeiras, como facilitadores da interação profissional de saúde/usuário, diminuindo a assimetria dessa relação:

"[...] era divertido, tinha gincana, tinha esclarecimentos, tinha brincadeira".

Tais recursos são considerados importantes veículos de comunicação e instrumentos eficientes de ensino e aprendizagem, além de propiciarem satisfação emocional imediata (Trezza, Santos, Santos, 2007; Torres, Hortale, Schall, 2003).

Os usuários realizaram considerações em relação ao local e ao horário das atividades e, também, aos profissionais que conduziam os grupos educativos, conforme se verifica nos discursos:

"[...] seria bom que tivesse aqui também (no bairro) para ficar mais perto".

"[...] dependendo da hora da reunião, muita gente não dava para ir [...]".

"Acho que é melhor ter [...] (outros) profissionais, para que cada um que tenha uma experiência nova poder passar [...]".

Em relação à logística dos grupos educativos, observou-se que estava estruturada de acordo com as condições dos profissionais. No entanto, a atividade educativa também deve considerar a realidade e o cotidiano dos participantes (Freire, 2007), buscando conhecer suas necessidades (Fernandes, Backes, 2010; Torres, Hortale, Schall, 2003). Isso porque não há um compromisso autêntico com a comunidade, se o profissional considera a realidade como algo estático, não a enxergando como uma totalidade, em permanente interação (Freire, 2007).

Ao não se considerarem os fatores que influenciam a participação dos usuários aos grupos educativos, fere-se um dos princípios da educação - ser acessível (OMS, 1991).

Quanto aos profissionais, a ESF é composta, obrigatoriamente, pelo médico, enfermeiro e profissionais de nível médio. O cirurgião-dentista está presente em algumas modalidades de equipes (Brasil, 1997). Entretanto, os usuários referem-se à necessidade de outros profissionais, cuja formação não é mencionada. Caso sejam fisioterapeutas, farmacêuticos ou psicólogos, dentre outros, faz-se necessário pesquisar se realmente são necessárias outras categorias profissionais, muitas delas já reivindicando seu espaço na ESF.

Ressalta-se a existência dos Núcleos de Apoio à Saúde da Família (Nasf), já implantados em muitos municípios brasileiros, constituídos por profissionais de diferentes áreas de conhecimento, que atuam em conjunto com os profissionais da ESF, inclusive no desenvolvimento de Educação em Saúde (Brasil, 2010). Diante disso, a parceria das ESF com o Nasf se torna imprescindível para propiciar a multidisciplinaridade na prática educativa requerida pelos usuários. 


\section{Propostas pedagógicas}

Constatou-se, neste estudo, que a concepção de Educação em Saúde presente nas práticas educativas não se encontra embasada em uma abordagem determinada, sendo desenvolvida conforme a experiência dos profissionais, cuja formação foi assentada na pedagogia de transmissão (Villa, Aranha, 2009; Carvalho, Clementino, Pinho, 2008), mas já recebendo a influência da pedagogia problematizadora (Carvalho, Clementino, Pinho, 2008). Eles ora utilizavam a Pedagogia de Condicionamento, ora a de Transmissão, e ora a Problematizadora, mesmo que, na maioria das vezes, a intencionalidade fosse utilizar a prática dialógica.

A Pedagogia de Condicionamento, embora não praticada de forma explícita pelos profissionais, foi observada através de certas ações, como ditar regras a serem seguidas em situações específicas, associadas à cultura da barganha - o usuário participava de alguma atividade para obter recompensas (Bordenave, Pereira, 2007), como percebido nos relatos:

"[...] é difícil para gente está marcando consulta todo dia [...] quando tinha a reunião era mais fácil, porque ali a gente estava renovando receita, o médico estava sabendo o que estava acontecendo com a gente, eu sou a favor da reunião [...] basta a gente seguir as regras do médico certinho, dá para controlar". (E8)

"[...] fazia o teste do dedo (teste de glicemia capilar), ia medir a pressão (arterial) [...] o grupo é bom assim por conta dessas coisas". (E10)

Nessa perspectiva, o desenvolvimento da consciência crítica que deve ser suscitada durante o processo educativo fica comprometido (Gadotti, 2004).

Tal fato também foi observado em um estudo qualitativo, realizado em uma ESF, no distrito de Cachoeira do Campo, município de Ouro Preto, MG, em que os autores, ao se proporem conhecer a prática educativa desenvolvida por essa equipe, a partir dos relatos dos profissionais, verificaram o uso da pedagogia de condicionamento (Fernandes, Backes, 2010).

Mesmo que a motivação tenha sido a obtenção de consultas ou procedimentos, que, historicamente, têm sido demandados pela população (Fernandes, Backes, 2010), há de se esperar que a educação em saúde seja capaz de diminuir a procura por consultas, exames e medicamentos.

A adoção de uma concepção transmissiva, verificada nos depoimentos a seguir, talvez tenha acontecido pelo fato de alguns profissionais desconhecerem outra concepção de educação, ou como estratégia para alcançar maior número de pessoas: com temas específicos, objetivos definidos, menores custos e facilidade de organização do trabalho da equipe (Figueiredo, Rodrigues-Neto, Leite, 2010).

"Os médicos davam palestras sobre a saúde, (falando) o que a gente deveria fazer para evitar (o aumento da) pressão (arterial) [...]". (E3)

"Ele (educador) me deu uma lista e falou assim: você não pode tomar café, nem coca (refrigerante), nem comer pimenta [...] foi tirando um monte de coisa [...]".

"Eles falam para a gente fazer do jeito que mandam fazer". (E1)

A educação baseada na transmissão e reprodução do conhecimento faz com que o pensamento e a ação dos educandos sejam controlados pelos educadores (Freire, 2007); nesse sentido, o uso dessa concepção pedagógica durante a Educação em Saúde pode dificultar alcançar o seu objetivo de estimular os usuários a se responsabilizarem por sua saúde (Alves, 2005).

Resultados semelhantes foram observados em estudo realizado com enfermeiros que atuavam em ESF de 12 cidades do Rio Grande do Sul, com intuito de identificar a finalidade do processo comunicacional nas atividades em grupo, o qual verificou que a educação em saúde, muitas vezes, tem sido conduzida de forma unidirecional, por meio da transmissão de conteúdos (Cardoso et al., 2011). 
Outro estudo realizado na cidade de Maringá, PR, também com enfermeiros atuantes em ESF, ao investigar a prática de trabalho desses profissionais com as famílias, constatou que as atividades educativas estavam pautadas na transmissão vertical de informações a um usuário passivo, esperando a modificação do seu comportamento de acordo com o que é recomendado (Oliveira, Marcon, 2007).

A concepção da educação em saúde pelos membros de uma ESF (agentes comunitários de saúde, médico, enfermeira), como um instrumento de repasse de informações e explicações sobre as atitudes que os profissionais de saúde consideram como corretas, também foi verificada no estudo anteriormente citado, realizado no distrito de Cachoeira do Campo, município de Ouro Preto, MG (Fernandes, Backes, 2010).

Há que se considerar que a pedagogia de transmissão utilizada nas atividades educativas pode proporcionar, à população, o conhecimento produzido cientificamente, podendo ampliar informações e conhecimentos já existentes; no entanto, a aplicação desse conhecimento a sua realidade pode ser dificultada, pela sua postura passiva durante o processo de aprendizagem (Figueiredo, Rodrigues-Neto, Leite, 2010). Nesse sentido, pode-se perder uma das principais finalidades da Educação em Saúde, a de possibilitar a aplicação desses conhecimentos ao cotidiano dos participantes (Alves, 2005).

A Pedagogia Problematizadora foi utilizada nos grupos, pelos profissionais, por acreditarem que seria a melhor forma de envolver os usuários, estimulando-os a falarem sobre os seus problemas de saúde, contextualizando suas experiências, esclarecendo dúvidas, contribuindo para a construção do seu próprio conhecimento, não se restringindo às questões da doença, como verificado nos discursos a seguir.

O uso dessa concepção pedagógica é fundamental para o perfil dos participantes desse estudo, já que, por muito tempo, assumiram uma condição de sujeito passivo, e, por meio da prática educativa problematizadora, torna-se possível assumir uma postura ativa sobre o cuidado com sua saúde (Freire, 2007).

“[...] porque às vezes a gente não vai saber chegar e falar, (o educador) perguntando a pessoa está mais disposta a falar [...]". (E2)

"[...] a gente aprendia muito, era tipo um debate, todo mundo se abria [...]". (E9)

"[...] quem quisesse falar, quem quisesse perguntar alguma coisa podia perguntar, quem não entendeu poderia pedir um esclarecimento e eles (educadores) ajudavam a gente, dependia da gente [...]". (E3)

“[...] talvez a gente até estivesse com o problema que a pessoa estava perguntando por ele e a gente ia aprendendo [...] a experiência (do outro participante) assim é muito bom para a gente". (E10)

Moore et al. (2008) ressaltam que os programas educativos são mais intensos e frequentes quando há uma interação pessoa com pessoa, proporcionando uma maior retenção dos conhecimentos e benefícios para a saúde.

Durante o processo educativo, o educando deve ser o agente da aprendizagem, e os educadores poderão ajudá-lo na construção dos conhecimentos (Perrenoud, 2005). Observou-se, nesse estudo, que o usuário se reconhece como sujeito da própria educação, considerando o profissional como um facilitador do processo educativo, o que é muito importante para o entendimento do seu papel na transformação da realidade.

Ressalta-se que a mobilização dos saberes adquiridos e a assimilação de outros saberes necessários ao processo educativo (Perrenoud, 2005) são possíveis ao se estimular o usuário a falar, já que a sua expressão natural poderá estar limitada.

O estudo qualitativo realizado na perspectiva de enfermeiros atuantes em equipes de saúde da família de municípios do Rio Grande do Sul tem demonstrado que, apesar de os trabalhadores das ESF reconhecerem a importância do dialogismo em sua prática educativa e como um diferencial para o processo de trabalho em saúde, a sua aplicação é limitada (Cardoso et al., 2011). Autores associam esse 
fato à crença, de muitos profissionais de saúde, de realmente serem os detentores do saber (Fernandes, Backes, 2010); e ainda à falta de conhecimentos e capacitação dos profissionais para aplicação da pedagogia problematizadora (Fernandes, Backes, 2010; Figueiredo, Rodrigues-Neto, Leite, 2010).

Diante do exposto, pode-se afirmar que, mesmo com as vantagens e desvantagens de um modelo pedagógico sobre o outro, não houve predomínio de uma concepção, pois as ações educativas, tanto dos profissionais como dos usuários, estão em construção, incorporando inovações, sem, no entanto, se desvincularem totalmente do modelo hegemônico. Contudo, percebe-se uma satisfação maior do usuário com a pedagogia problematizadora, como visto na seguinte fala:

"(O grupo de Educação em Saúde) é bom, porque aí já conversa [...], fica mais alegre [...] a gente vai distraindo [...] me sinto bem [...]". (E1)

A combinação das pedagogias de condicionamento, transmissão e problematização durante as práticas educativas também foi observada em uma ESF do distrito de Cachoeira do Campo, município de Ouro Preto, MG, conforme verificado no estudo qualitativo de Fernandes e Backes (2010).

A utilização concomitante dessas pedagogias pode, até mesmo, ocorrer por uma tentativa do profissional de saúde de superar as pedagogias de condicionamento e transmissão, que estão fortemente inseridas na sua prática profissional (Figueiredo, Rodrigues-Neto, Leite, 2010; Renovato, Bagnato, 2010).

Há que se considerar que as formas pedagógicas não existem em estado puro, porque não existe uma sociedade abstrata que seria totalmente conservadora ou totalmente libertadora, já que a sociedade não é uma entidade acabada, mas em contínua transformação (Gadotti, 2004).

\section{Os temas discutidos}

Os temas discutidos nos grupos de Educação em Saúde estavam relacionados aos fatores de risco, ao tratamento e às complicações das doenças, conforme os depoimentos dos participantes:

“[...] a orientação (era) para não comer massas, doces [...]; fazer caminhada; usar o remédio direitinho. Aí eu achei bom, porque também eles (profissionais de saúde) ensinaram a posição da gente (aplicar) a insulina. Eu lembro que eu estava tomando errado, daí lá eles orientaram direitinho, eu aprendi com eles [...]". (E8)

"[...] se eu não cuido da minha saúde o que pode acontecer comigo é um infarto, é um derrame, que pode me jogar em cima de uma cama [...]. (E2)

Tal fato assemelha-se aos resultados encontrados em estudo realizado em ESF em Cachoeira do Campo, município de Ouro Preto, MG (Fernandes, Backes, 2010). De forma similar, enfermeiros de ESF do Rio Grande do Sul direcionavam suas ações educativas às necessidades ou alterações orgânicas dos usuários (Cardoso et al., 2011). Os conteúdos das práticas educativas dos enfermeiros das ESF de Maringá, PR, também estavam voltados para questões curativas ${ }^{4}$ (Oliveira, Marcon, 2007).

Segundo os participantes do presente estudo, também haviam discussões de temas relacionados à saúde:

\author{
${ }^{4} \mathrm{O}$ conteúdo das \\ atividades \\ educativas estava \\ baseado em \\ orientações sobre \\ o comportamento \\ adequado frente \\ ao controle das \\ enfermidades, o \\ uso correto da \\ medicação, a \\ observância de \\ dietas e o \\ esclarecimento \\ sobre as \\ patologias.
}


"Os médicos davam palestras sobre a saúde, o que a gente deveria fazer para evitar o problema de pressão (hipertensão arterial) [...]". (E3)

"Ele (o médico) falou [...] quanto mais tranquila ficar, mais a pressão (arterial) também fica melhor, apesar de [...] não ter muito jeito, com os problemas da vida, a gente não ficar nervosa, isso aí é uma coisa difícil da gente conseguir".

Embora, em alguns momentos, tenham sido discutidas questões sobre promoção da saúde, o fato de os profissionais organizarem os grupos por doença pode contribuir para que os usuários não tenham clareza sobre a concepção de saúde e de doença.

Tal fato pode tornar a educação em saúde reducionista, já que não se ancora no conceito ampliado de saúde e na promoção em saúde, que devem nortear as práticas educativas (Rocha, Schall, Lemos, 2010; Schall, Struchiner, 1999).

Em estudo realizado em uma ESF sobre a prática educativa desenvolvida pela equipe, na percepção dos seus integrantes, verificou-se também a discussão sobre o funcionamento do sistema público de saúde e, especificamente, da ESF, o que não foi observado no presente estudo (Fernandes, Backes, 2010).

Nesse contexto, torna-se importante a superação da concepção de saúde como ausência de doenças e do predomínio de aspectos médicos e biológicos, que historicamente tem norteado as práticas educativas e tem sido aceita pela população (Fernandes, Backes, 2010; Renovato, Bagnato, 2010).

As práticas educativas devem se constituir em instrumentos para a compreensão do processo saúdedoença como um fenômeno entremeado, também, por questões políticas, sociais e econômicas, que devem transpor as dimensões individuais, além de assumirem uma postura ativa do cuidado com a saúde (Fernandes, Siqueira, 2010; Renovato, Bagnato, 2010).

Outro aspecto concernente aos temas discutidos é a não-participação dos usuários na escolha das temáticas a serem trabalhadas nas atividades educativas, segundo este relato:

“Não (podia escolher os temas dos grupos), eles já vinham com aquilo certo que ia falar, por exemplo: um dia falava de alimentação, outro dia de esporte, outro dia de outra coisa lá que estava dentro daquele problema que a gente tem". (E3)

Apesar de os grupos educativos serem por temas, definidos a priori pelos profissionais de saúde, seguindo a recomendação do Ministério da Saúde (Brasil, 1997), foram abordadas, muitas vezes, questões de interesse dos usuários, ao se utilizar uma prática problematizadora.

Os temas funcionavam como questões norteadoras, como primeiro passo para as discussões. Embora não estivesse definido o desenvolvimento de tais discussões, notou-se, nos relatos abaixo, que estavam sendo alcançadas melhorias em relação à saúde:

"[...] melhorou (a saúde) porque eu perdi peso [...] mudei a alimentação [...] a diabetes ficou controlada". (E9)

"[...] minha pressão (arterial) controlou em vista do que era [...]".

É na realidade que educadores e comunidade devem buscar o conteúdo programático da educação, ao investigarem o universo temático dos participantes ou o conjunto de seus temas geradores. $\mathrm{O}$ momento desse buscar inaugura o diálogo da educação como prática da liberdade (Freire, 2005).

\section{A educação em saúde propicia a aprendizagem significativa}

Esta categoria revelou a educação em saúde como propiciadora de aprendizagem significativa, de forma que os conhecimentos construídos durante as atividades educativas contribuíam para a transformação da prática dos usuários quanto ao cuidado com a sua saúde. 
A educação, ainda que ancorada nas pedagogias de condicionamento e de transmissão, acaba por conduzir à aprendizagem. Não se trata de um aumento quantitativo de conhecimentos, mas de uma transformação intelectual do indivíduo (Bordenave, Pereira, 2007).

Entretanto, quando as ações educativas são norteadas pela pedagogia problematizadora, a aprendizagem passa a ter um significado para a prática do educando, de modo a transformá-la (Freire, 2005).

A aprendizagem significativa acontece quando aprender algo novo é importante para o educando. Geralmente, isso ocorre quando a novidade responde a uma das suas indagações e/ou quando o conhecimento novo é construído a partir de um diálogo com o que já era sabido anteriormente, contribuindo para transformar as suas práticas (Brasil, 2005).

Nos discursos dos usuários, ficou evidente que a Educação em Saúde propiciou a aprendizagem significativa:

“[...] a gente aprendeu muita coisa com ele (educador) [...]. Conscientizei e aprendi o que eu sigo [...]. Quando a gente aprende, a gente pratica, só não pratica mesmo quem não quer, porque aprendeu $[\ldots]^{\prime \prime}$ (E2)

"(Os outros participantes aprendem) porque vêem o exemplo da gente [...] quando é uma coisa que a gente faz e não vê resultado a pessoa desanima, mas a pessoa vendo resultado aí anima". (E2)

"[...] os daqui de casa fazem as mesmas coisas que eu faço [...]. Eles não foram (nos grupos de educação em saúde) mais eles sabem, porque eu falei (o que aprendi) [...]". (E1)

Além disso, verificou-se que o indivíduo, ao transformar a sua prática, também modifica o meio em que vive e se torna um disseminador dos conhecimentos adquiridos, transformando-se em um agente de mudança social (Pichón-Riviére, 1998). Tem-se aí a educação realizada por pares (Pérez-Escamilla et al., 2008), comprometida com o desenvolvimento da solidariedade e da cidadania, requerida pela educação em saúde (Rocha, Schall, Lemos, 2010).

Cardoso et al. (2011) verificaram em seu estudo que, mesmo com a realização de práticas educativas pautadas na transmissão de conteúdos, os usuários também se tornaram propagadores dos conhecimentos aprendidos em suas relações intracomunitárias.

Evidências internacionais têm sugerido que a educação por pares pode ter um impacto positivo sobre os comportamentos dos indivíduos relacionados ao autocuidado com o diabetes, à amamentação, à alimentação e ao conhecimento nutricional (Pérez-Escamilla et al., 2008).

Os ACS foram considerados por Pérez-Escamilla et al. (2008) como importantes educadores pares, já que são membros da comunidade e servem como conectores entre o serviço de saúde e os usuários para promoção da saúde, apresentando, geralmente, o mesmo status socioeconômico e experiências sociais e culturais similares às da comunidade a que serve. Têm contribuído para a melhoria do conhecimento, das condições clínicas, do autocuidado e mudanças de comportamento dos portadores de diabetes.

Vale ressaltar que esse processo de troca de conhecimento entre os pares reflete a importância do saber popular, da contextualização da realidade, da história e das vivências dos usuários, importantes para o processo de educar em saúde.

\section{A educação em saúde favorece mudanças na saúde do usuário}

A educação é considerada o elemento-chave para se realizarem as mudanças necessárias para tornar a saúde possível a todos (OMS, 1991).

Nesta categoria, evidenciaram-se mudanças na saúde dos usuários favorecidas pelas atividades educativas, quanto aos hábitos de vida, ao exercício da autonomia e à responsabilização pelo cuidado com a saúde. 
As atividades educativas em saúde possibilitaram mudanças no cotidiano do usuário (Alves, 2005), em relação à procura pelo serviço, à adesão ao tratamento ou ao cuidado com a sua própria saúde, independentemente da pedagogia utilizada (Gadotti, 2004), como se percebeu nos discursos a seguir:

\footnotetext{
"Mudou muita coisa para melhor, [...] no início eu aprendi alimentar, eu reaprendi e com as caminhadas eu melhorei minha pressão (arterial). [...] Depois que eu passei (a praticar) essas atividades [...] eu melhorei muito". (E3)

“[...] eu sempre vivia assim com a glicose alta [...] depois que eles explicaram, hoje (o diabetes) é sempre controlado [...]". (E4)
}

Reforça-se, nas falas dos participantes acima, que o educando deve possuir o papel de agente de mudança, sendo a realidade o seu objeto. Quando ele assume essa responsabilidade, atribui a si a exclusividade da atuação transformadora (Freire, 2007), o que foi percebido neste estudo entre os adultos e os idosos. No entanto, tais mudanças estão mais centradas nas doenças, talvez pelo fato de as atividades educativas não privilegiarem tanto as discussões sobre a prevenção de doenças e a promoção de saúde, que deveriam nortear a educação em saúde (Rocha, Schall, Lemos, 2010).

A aprendizagem construída a partir da vivência de experiências significativas resulta na aquisição de uma confiança maior na própria capacidade de aprender e de realizar atividades que satisfaçam suas necessidades (Bordenave, Pereira, 2007). Desse modo, o usuário sai de uma posição de passividade, deixando de ser dependente das ações dos profissionais de saúde e não mais acreditando que é somente por intermédio destes que poderá obter saúde. A educação cumpre aí o seu papel de libertação (Bordenave, Pereira, 2007; Freire, 2005).

Evidenciou-se que a atividade educativa estimulou o usuário ao exercício da autonomia e à responsabilização pelo cuidado com a saúde, o que pode ser observado nesses relatos:

"Hoje eu cuido [...]. Os médicos, os enfermeiros e os agentes (ACS) preocupam com a saúde da gente, mais a gente tem que preocupar mais ainda [...]". (E9)

\footnotetext{
"Sinto que antes eu ia direto (a ESF), muitas vezes porque a pressão (arterial) estava alta, [...] do ano passado para cá nunca mais eu fui ao médico [...]". (E2)

“[...] se eu não cuido da minha saúde o que pode acontecer comigo é um infarto, é um derrame [...]. Tenho consciência mais disso do que antes [...] depois que (tive) consciência, a minha vida hoje melhorou [...]". (E2)
}

Os educandos, anteriormente, pareciam considerar o serviço de saúde como o responsável pela sua saúde. Por meio das práticas educativas, conscientizaram-se da sua responsabilidade no autocuidado, sentindo-se mais capacitados para o exercício do cuidado com a saúde, já que o acesso ao conhecimento os instrumentaliza para isso (Renovato, Bagnato, 2010). Nesse contexto, os indivíduos tornam-se cada vez mais independentes dos profissionais e serviços de saúde, o que é facilitado por meio da prática educativa reflexiva (Perrenoud, 2005), atingindo o conceito ampliado de saúde como a capacidade de tomar decisões e controlar a própria vida (OMS, 1986).

Para Cardoso et al. (2011), a comunicação dialógica é uma ferramenta imprescindível para a promoção da corresponsabilidade dos usuários, quanto aos cuidados com a sua saúde.

Pode ser visto, nesse trabalho, que a educação em saúde é um processo, em que os usuários, a princípio, valorizam as consultas médicas, que deixam de ser procuradas a todo instante quando eles assumem maior autonomia sobre sua própria saúde.

O usuário, ao ampliar os seus conhecimentos sobre o processo saúde-doença, sente-se mais capacitado para cuidar da sua saúde, já que se conscientizou dos riscos, dos cuidados necessários, das complicações e, também, da sua responsabilidade, o que pode estimulá-lo a buscar a promoção de sua saúde, e não exclusivamente a cura de sua doença. 
Ademais, tem se verificado impacto econômico produzido pelos programas de Educação em Saúde para a vida do indivíduo e da sociedade (O'Neill, 2008).

\section{Considerações finais}

Os grupos educativos em uma ESF em Montes Claros foram realizados, em sua maioria, no próprio território, em horários predefinidos pela equipe, embasados nas concepções pedagógicas por condicionamento, transmissão e problematização. Os temas discutidos eram mais relacionados às questões de doença, e menos à promoção da saúde. Tais grupos foram avaliados satisfatoriamente pelos usuários.

Há que se considerar o perfil dos participantes nos grupos, evidenciado por adultos e idosos com pouca escolaridade, que vivenciaram por muito tempo uma educação prescritiva, centrada no profissional de saúde e em condição de sujeito passivo. A sua participação regular nas atividades educativas favoreceu a aprendizagem significativa, resultando em mudanças nos seus hábitos de vida, no exercício da autonomia e responsabilização pelo cuidado com a sua saúde, tornando-os sujeitos ativos no cotidiano de sua saúde e disseminadores dos conhecimentos construídos.

Sugere-se que a educação em saúde seja utilizada pelos profissionais de forma dialógica e sistemática, valorizada pelos gestores e profissionais, buscando maior inserção dos usuários, com ações facilitadoras que considerem a realidade local e suas necessidades - como flexibilização dos horários, valorização da pedagogia problematizadora, discussões de temáticas sugeridas a priori pelos usuários e relacionadas, também, à promoção de saúde e prevenção de doenças.

Para que isso se efetive, é necessário que os profissionais de saúde participem de programas de Educação Permanente, para que estejam capacitados para as práticas de Educação em Saúde.

Espera-se que este trabalho contribua para a reflexão dos profissionais de saúde e gestores, sobre o potencial de transformação da prática educativa, de modo que entendam os grupos de educação em saúde, não como uma atividade a mais a ser realizada, mas como alicerce que reorienta a atenção à saúde; e, nesse sentido, possam mudar a sua abordagem durante os grupos educativos, tornando-se facilitadores no processo ensino-aprendizagem.

É importante que as práticas educativas em saúde sejam realizadas para a população em geral, com vistas à promoção de saúde, e não centrada na doença, na perspectiva de romper com o paradigma biologicista e curativista.

\section{Colaboradores}

Maria Fernanda Santos Figueiredo responsabilizou-se pela elaboração do projeto de pesquisa, coleta de dados, análise dos dados e produção do manuscrito. João Felício Rodrigues Neto e Maisa Tavares de Souza Leite responsabilizaram-se pela orientação da elaboração do projeto de pesquisa, coleta de dados e análise dos dados, bem como pela produção do manuscrito.

\section{Referências}

ALVES, G.G.; AERTS, D. As práticas educativas em saúde e a estratégia saúde da família. Cienc. Saude Colet., v.16, n.1, p.319-25, 2011. Disponível em: <http:// www.scielosp.org/pdf/csc/v16n1/v16n1a34.pdf>. Acesso em: 25 nov. 2011. doi: $10.1590 /$ S1413-81232011000100034. 
ALVES, V.S. Um modelo de educação em saúde para o Programa Saúde da Família: pela integralidade da atenção e reorientação do modelo assistencial. Interface - Comunic., Saude, Educ., v.9, n.16, p.39-52, 2005. Disponível em: <http://www.scielo.br/pdf/ icse/v9n16/v9n16a04.pdf>. Acesso em: 15 out. 2007. doi: 10.1590/S141432832005000100004 .

BORDENAVE, J.D.; PEREIRA, A.M. Estratégias ensino-aprendizagem. 28.ed. Petrópolis: Vozes, 2007.

BRASIL. Ministério da Saúde. Secretaria de Atenção à Saúde. Departamento de Atenção Básica. Diretrizes do NASF: Núcleo de Apoio a Saúde da Família. Brasília: Ministério da Saúde, 2010.

Ministério da Saúde. Secretaria de Gestão do Trabalho e da Educação na Saúde. Departamento de Gestão da Educação na Saúde. A educação permanente entra na roda: pólos de educação permanente em saúde: conceitos e caminhos a percorrer. Brasília: Ministério da Saúde, 2005.

Ministério da Saúde. Secretaria de Assistência à Saúde. Coordenação de Saúde da Comunidade. Saúde da família: uma estratégia para a reorientação do modelo assistencial. Brasília: Ministério da Saúde, 1997.

CARDOSO, L.S. et al. The purpose of the communication process of group activities in the Family Health Strategy. Rev. Latino-Am. Enferm., v.19, n.2, p.396-402, 2011. Disponível em: <http://www.scielo.br/pdf/rlae/v19n2/23.pdf>. Acesso em: 23 maio 2011. doi: 10.1590/S0104-11692011000200023.

CARVALHO, V.L.; CLEMENTINO, V.Q.; PINHO, L.M. Educação em saúde nas páginas da REBEn no período de 1995 a 2005. Rev. Bras. Enferm., v.61, n.2, p.243-8, 2008. Disponível em: <http://www.scielo.br/pdf/reben/v61n2/a16v61n2.pdf>. Acesso em: 4 jan. 2009. doi: 10.1590/S0034-71672008000200016.

FERNANDES, M.C.P.; BACKES, V.M.S. Educação em saúde: perspectivas de uma equipe da Estratégia Saúde da Família sob a óptica de Paulo Freire. Rev. Bras. Enferm., v.63, n.4, p.567-73, 2010. Disponível em: <http://www.scielo.br/pdf/reben/v63n4/ 11.pdf>. Acesso em: 23 maio 2011. doi: 10.1590/S0034-71672010000400011.

FERNANDES, W.R.; SIQUEIRA, V.H.F. Educação em saúde da pessoa idosa em discursos e práticas: atividade física como sinônimo de saúde. Interface - Comunic., Saude, Educ., v.14, n.33, p.371-85, 2010. Disponível em: <http://www.scielo.br/pdf/ icse/v14n33/a11v14n33.pdf>. Acesso em: 23 maio 2011. doi: 10.1590/S141432832010000200011 .

FIGUEIREDO, M.F.S. A Educação em Saúde sob a percepção do usuário da Estratégia Saúde da Família em Montes Claros, Minas Gerais. 2010. Dissertação (Mestrado) Universidade Estadual de Montes Claros, Montes Claros. 2010.

FIGUEIREDO, M.F.S.; RODRIGUES-NETO, J.F.; LEITE, M.T.S. Modelos aplicados às atividades de educação em saúde. Rev. Bras. Enferm., v.63, n.1, p.117-21, 2010. Disponível em: <http://www.scielo.br/pdf/reben/v63n1/v63n1a19.pdf>. Acesso em: 6 jun. 2011. doi: 10.1590/S0034-71672010000100019.

FREIRE, P. Educação e mudanças. 30.ed. Rio de Janeiro: Paz e Terra, 2007.

Pedagogia do oprimido. 46.ed. Rio de Janeiro: Paz e Terra, 2005.

FREITAS, M.I.F. A Educação e a Saúde. Reme, v.14, n.4, p.457-8, 2010.

GADOTTI, M. Pedagogia da práxis. 4.ed. São Paulo: Cortez: Instituto Paulo Freire, 2004.

HABERMAS, J. Consciência moral e agir comunicativo. Rio de Janeiro: Tempo Brasileiro, 1989. 
LACERDA, W.A.; SANTIAGO, I.M.F.L. A participação popular na gestão local do Programa Saúde da Família em Campina Grande, Paraíba. Rev. Katál., v.10, n.2, p.197-205, 2007. Disponível em: <http://www.scielo.br/pdf/rk/v10n2/ a07v10n2.pdf >. Acesso em: 19 nov. 2011. doi: 10.1590/S141449802007000200007.

LALONDE, M. A new perspective on the health of canadians: a working document. Ottawa: Minister of Supply and Services Canada, 1974. Disponível em: <http:// www.hc-sc.gc.ca/hcs-sss/alt_formats/hpb-dgps/pdf/pubs/1974-lalonde/lalondeeng.pdf >. Acesso em: 25 nov. 2011.

MINAYO, M.C.S. O desafio do conhecimento: pesquisa qualitativa em saúde. 10.ed. São Paulo: Hucitec, 2007.

MOORE, T.J. et al. Weight, blood pressure, and dietary benefits after 12 months of a web-based nutrition education program (DASH for health): longitudinal observational study. J. Med. Internet Res., v.10, n.4, e.52, 2008. Disponível em: <http:// www.ncbi.nlm.nih.gov/pmc/articles/PMC2629362/>. Acesso em: 20 dez. 2010. doi: 10.2196/jmir.1114.

MORIN, E. A cabeça bem feita: repensar a reforma, reformar o pensamento. 7.ed. Rio de Janeiro: Bertrand Brasil, 2002.

O'NEILL, B. Calculation the Economic Impact of Health Educations Programs: Five Tools for Extension Educators. J. Extension, v.46, n.1, article 1TOT4, 2008. Disponível em: <http://www.joe.org/joe/2008february/tt4.php>. Acesso em: 20 out. 2009.

OLIVEIRA, R.G.; MARCON, S.S. Trabalhar com famílias no Programa de Saúde da Família: a prática do enfermeiro em Maringá-Paraná. Rev. Esc. Enferm. USP, v.41, n.1, p.65-72, 2007. Disponível em: <http://www.scielo.br/pdf/reeusp/v41n1/ v41n1a08.pdf>. Acesso em: 4 nov. 2010. doi: 10.1590/S008062342007000100009 .

ORGANIZAÇÃO MUNDIAL DE SAÚDE (OMS). Declaração de Sundsvall: Terceira Conferência Internacional de Promoção da Saúde. 1991. Disponível em: <http:// www.opas.org.br/promocao/uploadArq/Sundsvall.pdf>. Acesso em: 24 nov. 2011

Carta de Ottawa: Primeira Conferência Internacional sobre Promoção de Saúde. 1986. Disponível em: <http://www.opas.org.br/promocao/uploadArq/ Ottawa.pdf>. Acesso em: 24 nov. 2011.

Declaração de Alma-Ata: Conferência Internacional sobre os Cuidados Primários em Saúde. 1978. Disponível em: <http://www.opas.org.br/coletiva/ uploadArq/Alma-Ata.pdf>. Acesso em: 24 nov. 2011.

PÊCHEUX, M. O discurso: estrutura ou acontecimento. 3.ed. Campinas: Pontes, 2002.

PÉREZ-ESCAMILLA, R. et al. Impact of peer nutrition education on dietary behaviors and health outcomes among Latinos: a systematic literature review. J. Nutr. Educ. Behav., v.40, n.4, p. 208-25, 2008. Disponível em: <http://www.ncbi.nlm.nih.gov/ pmc/articles/PMC2746903/?tool=pubmed $>$. Acesso em: 23 maio 2011. doi: 10.1016/j.jneb.2008.03.011

PERRENOUD, P. Escola e cidadania: o papel da escola na formação para a democracia. Porto Alegre: Artmed, 2005.

PICHÓN-RIVIÈRE, E. O processo grupal. 6.ed. São Paulo: Martins Fontes, 1998.

RENOVATO, R.D.; BAGNATO, M.H.S. Práticas educativas em saúde e a constituição de sujeitos ativos. Texto Contexto Enferm., v.19, n.3, p.554-62, 2010. Disponível em: <http://www.scielo.br/pdf/tce/v19n3/a18v19n3.pdf>. Acesso em: 23 maio 2011. doi: $10.1590 /$ S0104-07072010000300018. 
ROCHA, V.; SCHALL, V.T.; LEMOS, E.S. A contribuição de um museu de ciências na formação de concepções sobre saúde de jovens visitantes. Interface - Comunic., Saude, Educ., v.14, n.32, p.183-96, 2010. Disponível em: <http://www.scielo.br/pdf/ icse/v14n32/15.pdf $>$. Acesso em: 24 nov. 2011. doi: 10.1590/S141432832010000100015.

SCHALL, V.T.; STRUCHINER, M. Health education: new perspectives. Cad. Saude Publica, v.15, supl.2, s.4-6, 1999. Editorial. Disponível em: <http://www.scielo.br/pdf/ csp/v15s2/1282.pdf > . Acesso em: 24 nov. 2011. doi: 10.1590/S0102$311 \times 1999000600001$.

SILVA, K.L. et al. Educação em enfermagem e os desafios para a promoção de saúde. Rev. Bras. Enferm., v.62, n.1, p.86-91, 2009. Disponível em: <http://www.scielo.br/ pdf/reben/v62n1/13.pdf>. Acesso em: 26 nov. 2011. doi: 10.1590/S003471672009000100013.

TORRES, H.C.; HORTALE, V.A.; SCHALL, V. A experiência de jogos em grupos operativos na educação em saúde para diabéticos. Cad. Saude Publica, v.19, n.4, p.1039-47, 2003. Disponível em: <http://www.scielo.br/pdf/csp/v19n4/16853.pdf>. Acesso em: 21 jan. 2008. doi: 10.1590/S0102-311X2003000400026.

TREZZA, M.C.S.F.; SANTOS, R.M.; SANTOS, J.M. Trabalhando educação popular em saúde com a arte construída no cotidiano da enfermagem: um relato de experiência. Texto Contexto Enferm., v.16, n.2, p.326-34, 2007. Disponível em: <http:// www.scielo.br/pdf/tce/v16n2/a17v16n2.pdf>. Acesso em: 4 jan. 2009. doi: 10.1590/ s0104-07072007000200017.

VILLA, E.A.; ARANHA, A.V.S. A formação dos profissionais da saúde e a pedagogia inscrita no trabalho do Programa de Saúde da Família. Texto Contexto Enferm., v.18, n.4, p.680-7, 2009. Disponível em: <http://www.scielo.br/pdf/tce/v18n4/09.pdf>. Acesso em: 23 maio 2011. doi: 10.1590/S0104-07072009000400009.

FIGUEIREDO, M.F.S.; RODRIGUES NETO, J.F.; LEITE, M.T.S. Educación en salud en el contexto de la Salud de la Familia en la perspectiva del usuario. Interface - Comunic., Saude, Educ., v.16, n.41, p.315-29, abr./jun. 2012.

Se trata de comprender la perspectiva de los usuarios sobre Educación en Salud y su significado en lo cotidiano mediante investigación cualitativa, descriptiva y exploratoria. Han participado 11 usuarios registrados en un Equipo de Salud de la Familia en Montes Claros, estado de Minas Gerais, Brazil, con frecuencia igual o superior a cinco actividades en grupos educativos desarrollados en la unidad de salud en 2007. Los datos, obtenidos en entrevistas no estructuradas, se analizaron por el análisis del discurso. Los resultados revelan tres categorías empíricas: "La práctica de Educación en Salud en el Equipo de Salud de la Familia" y "La educación en salud proporciona un aprendizaje significativo", "La educación en salud favorece cambios en la salud del usuario". Los grupos educativos cuyas sesiones se han utilizado pedagogías de condicionamiento, transmisión y/o problematización, favorecen un aprendizaje significativo del usuario, facilitando cambios en los hábitos de vida, en el ejercicio de la autonomía y en la responsabilización por la salud.

Palabras clave: Educación en Salud. Aprendizaje. Atención Primaria a la Salud. Salud de la Familia. Investigación cualitativa. 
